\title{
Role of MHC restriction in allogeneic immune responses to cancer
}

\author{
Gomase V.S.*and Parundekar A.N. \\ *School of Technology, S.R.T.M. University, Sub-Centre, Latur, 413531, \\ gomase.viren@gmail.com \\ Padmashree Dr. D. Y. Patil University, CBD Belapur, Navi Mumbai, 400614, India
}

\begin{abstract}
1. Introduction
Cancer is a disease of genes, with a myriad of them showing altered expression, either contributing to the cause of cancer, or consequence of it. These changes in gene expression make many alterations in cell physiology like: - 1) self-sufficiency in growth signals, 2) insensitivity to anti-growth signals, 3) evasion of apoptosis, 4) limitless replicative potential, 5) sustained angiogenesis, and 6) tissue invasion and metastasis [1]. Oncogenesis, as a result of overactivity of growth factor receptors, cytokine receptors and oncoproteins, coordinates immune evasion [2]. Tumor cells display different antigens coupled with MHC I than the normal cells. Ideally our immune system employs a defense mechanism called 'immunological surveillance' to detect and destroy these cancer cells, a concept proposed by Elrich in 1909 [1, 2].There are several mechanisms of escape from the immune surveillance like immunoselection of tumor antigennegative variants, the downregulation of MHC class I expression, suppressive T cells, and the elaboration of immunosuppressive cytokines and other factors [3]. Professional APCs are endowed with the ability of 'cross presentation' i.e., presentation of antigens on MHC class I molecules. Cross presentation can either lead to tolerance or to immunity. If antigens are obtained themselves alone, it leads to tolerance. If antigens are acquired with immunostimulatory signals, it leads to immunity. The phenomenon of cross presentation is essential for development of immunity to tumors [4]. Immunotherapy has long been viewed as an alternative to overcome the serious side effects of treatments like chemotherapy and radiotherapy. The immune system has the potential to either promote or delay tumor onset and progression, the effectiveness of immune surveillance and the efficacy of immunotherapy depend on the balance between these diametric opposites. In leukemia one treatment option is replacing the bone marrow. Often bone marrow infused from allogeneic donor to the patient induces a beneneficial graft vs leukaemia or to say in general graft vs tumor effect In this review we are exploring strategies, in context of $\mathrm{MHC}$ restriction to contain this graft vs host disease and at the same time retain a sustained antitumor[here mainly anti-leukemia] effect. Further the use of this principle in conjunction with immunobiotechnology approaches like siRNA and allogeneic therapeutic vaccines can be extended to solid tumors.
\end{abstract}

\section{MHC Restriction And Alloreactivity}

The term alloreactivity denotes the immunologic reactions that occur when tissues are transplanted between two individuals within the same species. T cells as a part of their maturation process undergo positive selection i.e., only those cells which are able to recognize self $\mathrm{MHC}$ survive. However, self MHC Restriction is not absolute on average. On an average $1-24 \%$ of T cells are able to recognize a foreign haplotype. Also average self MHC Restriction and average alloreactivity are inversely correlated [5]. Thymic positive selection and the mode of alloreactivity induction are the major independent factors determining the patterns of alloantigen recognition [6]. Homology between the selecting ligand and an alloantigen can influence the avidity of the $T$ cell repertoire for the alloantigen [7]. The structural basis for the crossreactivity between different $\mathrm{MHC}$ alleles is the similarity in amino acid sequence of that part of the molecule predicted to make contact with the $T$ cell receptor $[T c R][8]$. Alloantigen recognition can be peptide independent, peptide specific, or peptide dependent. After transplantation, host alloantigens may be presented directly by host APCs or be crosspresented by donor APCs[4]. Transplantation tolerance across major histocompatibility complex [MHC] occurs spontaneously in nature, as evidenced by the fact that pregnant females do not reject their conceptus [9]. HLA-G seems to get up-regulated in tumor cells that may favor their escape from anti-tumor immune responses [10]. 


\section{Graft vs Host Disease}

Acute GVHD is a major cause of mortality in allogeneic bone marrow transplantation. It is a potentially life-threatening immune attack against the tissues of an alloHCT recipient by mature donor $\mathrm{T}$ cells contained within the graft [11]. The syndrome manifests symptoms of diarrhea, weight loss, skin changes, and liver abnormalities. HLA proteins are essential to the activation of allogeneic $T$ cells There are three prerequisites for the development of graft-versus-host disease [GVHD]: first, the presence of immunocompetent cells in the donor inoculum; second, the inability of the recipient to reject the donor cells; and third, a histocompatibility difference between the donor and recipient [12]. The immunobiology of GVHD can be explained in 3 stages-

Activation of Antigen Presenting Cells:- In the first phase, high-dose chemoradiotherapy causes damage to host tissues, including a self-limited burst of inflammatory cytokines such as tumor necrosis factor [TNF]-alpha and interleukin 1, described as cytokine storm. [13, 14] This affects host antigen presenting cells [APCs], by increasing their maturation and upregulation of costimulatory molecules/cytokines and helps fuel the alloreactive donor $T$ cell response [15]. Donor $T$ cell activation- is characterized by donor $T$ cell interaction with host APCs and subsequent proliferation, differentiation and secretion of cytokines. Cytokines such as IL-2 and IFN-gamma enhance T-cell expansion, induce cytotoxic T cells [CTL] and natural killer [NK] cell responses and prime additional mononuclear phagocytes to produce TNF-alpha and IL-1 [16]. Nogueira-Martins MF proved that B-1 and B cells participate in alloimmune response. They observed a delay in rejection kinetics of B-1 deficient mice as compared to wild type mice [17]. Effector phase:- These inflammatory cytokines in turn stimulate production of inflammatory chemokines, thus recruiting effector cells into target organs [14.] The effector phase that leads to the GVHD target organ damage is a complex cascade of multiple cellular and inflammatory effectors that further modulate each others responses either simultaneously or successively. Effector mechanisms of acute GVHD can be grouped into cellular effectors [e.g., CTLs] and inflammatory effectors such as cytokines [14]. There is a major histocompatibility complex [MHC] restriction between P-HSCs and stromal cells; normal P-HSCs can proliferate and differentiate efficiently in collaboration with MHC class I-compatible stromal cells [18]. A successful allogeneic [allo] BMT can be executed by recruiting donor bone marrow stromal cells. This may include injection of whole bone marrow cells [BMCs] including stromal cells via the portal vein [PV] [19]. The antigen Stro1 is a marker for a pure primitive Mesenchymal stem cell subset. The Stro-1enriched immunosuppressive effect is linked to increased gene expression for soluble inhibitory factors such as interleukin-8 [IL-8], leukemia inhibitory factor [LIF], indoleamine oxidase [IDO], human leukocyte antigen-G [HLA-G], and vascular cell adhesion molecule [VCAM1] [20]. MHCrelated peptide-induced antigen-specific unresponsiveness represents a novel form of immunomodulation. Several groups have now shown that peptides derived from conserved regions of both class I and II MHC molecules may inhibit the auto- and alloimmune response in vitro. Rationally designed peptides that mimic the putative interaction site of CD4 and the MHC class II molecule have been shown to have significant benefits in animal models of experimental bone marrow transplantation [21].

\section{Graft vs Tumor}

The Graft-versus-Tumor [GVT] effect occurs if the malignant cells are the targets of the graft vs host reaction [22]. The target molecules involved in the allo-immune graft-versus-tumor reaction are tumor-specific antigens, tumor-associated antigens, and tissue- and cell-specific minor histocompatibility antigens. Recognition of minor histocompatibility antigens [mHAs] by donor $\mathrm{T}$ cells contributes to antitumor responses [23]. Alloreactive CD8+ T cells targeting minor histocompatibility antigens $[\mathrm{MiHA}]$ on malignant cells of the recipient play a pivotal role in graftversus-tumor responses [24]. In T cell depleted HLA-haploidentical HCT, natural killer cells play a role [25]. The therapeutic effect of allogeneic hematopoietic stem cell transplantation [HSCT] aimed against haematological malignancies is attributed to graft-versus-leukemia effect that is dependent on donor T Iymphocytes. Dissociation of GVL effects from GVHD has been the ultimate goal of allogeneic BMT in the treatment of hematologic malignancies [26]. MHC mismatched mixed chimeras are quite preferred against full chimeras for a robust GVL response. Also HLA mismatch combinations have been associated with decreased risk of relapse [27]. Diverse $\mathrm{T}$-cell response specific for minor $\mathrm{H}$ and tumor-associated antigens expressed by $\mathrm{CLL}$ 
predicts an effective graft-versus-leukemia response after NM-HSCT [28]. HLA-class II is predominantly expressed under noninflammatory conditions on hematopoietic cells. MHC alloreactivity and GVL are separable from GVHD when donor T cells are administered as delayed DLI. GVL effects of delayed DLI are dependent on cooperative interactions between donor CD4+ and CD8+ T cells [28, 29]. Certain tumor associated antigens which includes cancer-testis antigens like PRAME are overexpressed in many acute and chronic leukaemias. PRAME specific CTLs obtained from healthy bonors display a significant avidity as compared to patient's CTL [PRAME specific] and can generate a selective GvL effect after allogeneic stem cell transplantation. CTL administration may be used in sequence with peptide vaccines to maintain long-term immune surveillance [30].

\section{Minor Histocompatibility Antigens}

Minor histocompatibility antigens [mHag] were originally identified as antigens causing graft rejection or graft-versus-host disease in human leukocyte antigen [HLA]-matched allogeneic transplantation [31]. Minor histocompatibility $[\mathrm{H}]$ antigens are polymorphic peptides that are presented on the cell surface by major histocompatibility complex class I or II molecules. These peptides are derived from any number of polymorphic genes throughout the genome that differ between the donor and recipient. These polymorphisms are often single nucleotide polymorphisms [SNPs], which result in amino acid sequence differences or differences in the expression of normal cellular proteins. In general, minor $\mathrm{H}$ antigen-encoding proteins are biallelic, encoding an immunogenic and a non-immunogenic allele. Individuals homozygous for the nonimmunogenic minor $\mathrm{H}$ allele can develop immune responses to cells expressing the immunogenic minor $\mathrm{H}$ allele [32, 33]. The first $\mathrm{mHA}$ to be described were those encoded by the $\mathrm{Y}$ chromosome; male recipients of female allografts experience both a higher severity of GVHD and more effective GVT responses, presumably due to recognition of Y-chromosome-encoded $\mathrm{mHA}$ by the female donor T cells [25]. Moreover, minor histocompatibility allo-antigens are not subjected to self tolerance [34].

\section{Strategies to Harness Graft vs Tumor Effect 6.1. Use of Immunomodulatory Cells \\ 6.1.1 Use of NK cells}

HLA disparity between hematopoietic stem cell [HSC] donor and recipient triggers NK-cell allorecognition. NK cell alloreactivity seems to reduce the risk of relapse in acute myeloid leukemia patients while improving engraftment and protecting against graft-vs.-host disease [GvHD][35]. The MHC constitutes a quality referential for the NK lymphocytes. A transformed somatic cell represses the expression of one or more of its class I HLA alleles, this absence of the self is perceived by the NK lymphocytes which proceed to its elimination through cytolysis [36]. AML and CML may be better target cells for NK cells than ALL because of their higher LFA1 expression, and they may be better able to provide activation signals to the NK cells [37]. High resolution molecular HLA typing of recipient and donor, positive identification of donor KIR genes, and the functional assessment of donor NK clones can identify haploidentical donors who are able to mount donor-vs.-recipient NK alloreactions [35].

\subsubsection{Role of NKT cells}

NK-T cells are CD3+ cells that express a distinct $V\{$ alpha\}24+ T-cell receptor [TCR] together with an NK cell marker [CD161] [37]. The expression of CD158b is downregulated with the occurrence of acute GVHD [38]. The alloreactions seem to be determined by the mismatched HLA class I ligands and their killer-cell immunoglobulin-like receptors [39]. NKT cells include a CD1d-reactive subset that influences immunity by rapidly producing large amounts of Th1 and/or Th2 cytokines. Shaulov A et al proved that granulocyte CSF treatment of allogeneic or autologous BM in vitro produced Th1 CD1d-reactive NKT cells which could stimulate anti-tumor responses [40]. Activation of NKT cells followed by activation of APCs and IL-12 production may lead to activation of NK cells and suppress GVHD in mismatched major histocompatibility complex combinations or may induce GVL effects [41]. 


\subsubsection{Regulatory $T$ cells}

Regulatory function of these cells is dependent on TCR stimulation, and hence are said to be specific in the regulation of alloimmune responses [42]. Several $\mathrm{Tr}$ subsets have been identified within CD4+ T cell populations. They can be type 1 [Tr1], characterized by secretion of IL-10 and TGF- $\beta$ with negligible production of IL- 4 or Th3, characterized by secretion of IL-10 and TGF- $\beta$, with concomitant dependence on IL-4 for functional differentiation and yet another categoty of suppressor CD4+ T cells, identifiable by their coexpression of CD25 [43]. Th1 and Th2 responses activate two pathways of alloantigen specific Tregs that can mediate transplant tolerance, the two pathways being dependent on the set of cytokines secreted by Th1 or Th2 cells [44, 45]. Li AH proved that serum dereived from patients with ALL can convert CD4 [+] CD25 [-] T cells to CD4 [+] CD25 [+] Tregs, thus contributing to immunosuppresion [46]. Cao J etal engineered CD4 [+] CD25 [-] T cells to express Foxp3. Coinjection with donor bone marrow cells into the recipient resulted in minimized GVHD without compromising GVL [47]. Use of exvivo expanded regulatory T cells encoding CD90 and thymidine kinase suicide gene gives us a modular control to prevent uncontrolled immunosupression [48]. Recent studies demonstrated that Extracorporeal Photochemotherapy downregulates the immune response and induces tolerance by regulatory $T$ cells. The basis of extracorporeal photopheresis is the reinfusion of leukocytes previously exposed to 8-methoxypsoralen [8-MOP] and ultraviolet A radiation [49].

\subsection{MiHag-based immunotherapy}

Genotypic disparity of SNP between transplantation donors and recipients in allogeneic haematopoeitic cell transplantation gives rise to $\mathrm{mHag}$ as non-self antigens for both the donor and the recipient [31]. The strategies for this therapy include adoptive cellular immunotherapy with mHAg-specific T cells; mHAg peptide, protein, mRNA or DNA vaccination selective immunodepletion of GVHD-instigating T cells; and mHAg-specific TCR gene transfer [50]. HA-1, a prototypic autosomal mHag derived from single nucleotide dimorphism $[\mathrm{HA}-1[\mathrm{H}]$ versus $\mathrm{HA}$ $1[R]]$ in the HMHA1 gene. The HA-1[H] peptide is restricted by HLA-A2 and is immunogenic in $\mathrm{HA}-1[\mathrm{R} / \mathrm{R}]$ into $\mathrm{HA}-1[\mathrm{H}]$ transplants [51]. The mHag HA-1 is aberrantly expressed in cancers of most entities albeit not in some solid tumors where hypermethylation in the promoter region inhibits its transcription. Hambach L, etal used DNA hypomethyating drug 5-aza-2'-deoxycytidine that induced HA-1 expression only and sensitized the tumor cells for adoptive immunotherapy [52]. HA-1 and HA-2 variability are not associated with the presence of cancer. So determination of HA-1 and HA-2 variability can be an important parameter for the selection of allogeneic stem cell donors, in particular for patients affected by hematologic malignancies without a tumorspecific molecular marker [53]. Meunier MC etal carried out an analysis of proliferative dynamics and persistence of $\mathrm{H} 7[\mathrm{a}]$ specific tumor cells after adoptive transfer and concluded that it may be advantageous to target MiHAs with a restricted tissue distribution in order to promote persistence of memory $\mathrm{T}$ cells and thereby minimize the risk of cancer recurrence [54]. Another popular potential therapeutic target is LRH-1 encoded by the gene P2X5. P2X5 is not expressed in prominent graft-versus-host-disease target tissues such as skin, liver and gut but highly expressed in malignant cells. De Rijke et al. found that the P2X5 gene of the HSCT recipient contained a deletion of a single nucleotide, resulting in a frameshift. HSCT donor T cells might be able to recognize peptides derived from the recipient's P2X5 gene product fragment following the frameshift [55, 56]. Stumph AN et al identified four 4 new HLA-DR-restricted minor histocompatibility antigens, which could be recognized by $T$ cells only on hematopoietic cells. They have suggested that CD4+ T cells administered late after alloSCT may selectively confer GVL without GVHD [57]. Vaccines that contain the patient's tumor cells which express the patient's miHAs, are also another alternative [58].

\subsection{Donor lymphocyte infusions}

Donor lymphocyte infusions [DLI] often are used after allo-SCT to augment the graft-versus-tumor effect [59]. DLI is being used as prophylaxis after SCT for patients with a high risk of relapse due either to advanced disease stage or in conjunction with T-cell-depleted grafts. For patients with relapsed chronic-phase CML, DLI is dramatically effective without other therapy. In case of an advanced-phase CML or acute leukemia, remission rates are low and often of short duration, hence $\mathrm{DLI}$ is therefore often given in conjunction with cytoreductive chemotherapy [60] 
Allospecific donor Tc2 cells result in reduced GVHD, and mediate a significant GVL effect [61]. A state of mixed chimerism is superior to complete donor chimerism because host-type APCs facilitate a DLI-induced GVL effect without severe GVHD [62].

\subsection{Allodepleted T cells}

An alternative approach to overcome the problem of alloreactivity is to selectively deplete the Tcell product of alloreactive cells expressing activation markers in response to alloantigen. Global $\mathrm{T}$ cell depletion has high mortality chances due to viral infections and disease relapse. Hence selective T cell depletion is preferred. Ge X etal proved that use of CD134-allodepleted grafts may improve allogeneic SCT by reducing GVHD without loss of pathogen-specific and leukemiaspecific immunity. Also compared to other markers CD134 is superior because of its negative baseline expression and rapid upregulation after activation [63]. Selective $T$ cell depletion of activation marker CD25 with an immunotoxin directed against it is also widely investigated [64]. To further increase the efficacy of the technique Tey SK etal, used a suicide gene, inducible caspase 9 [iCasp9], to transduce allodepleted $T$ cells, permitting their destruction should administration have adverse effects. The gene could be induced by a small molecule dimerizer, and it could induce more than $90 \%$ of apoptosis [65]. Another recent strategy is infusion of photoallodepleted T cells. In a mixed lymphocyte reaction, alloantigen-stimulated T cells uptake 4, 5dibromorhodamine methyl ester [TH9402] which preferentially localizes in mitochondria and when exposed to 500- to 600-nm wavelength visible light delivered through the Theralux device [Kiadis Pharma, Amsterdam, The Netherlands] becomes highly cytotoxic through oxidative damage [66].

\subsection{Use of dendritic cells}

Dendritic cells [DCs] are able to orchestrate innate and acquired immunity. Li YL et al pulsed bone marrow derived dendritic cells with tumor lysates to induce immunity against gastric cancer ex vivo. These cells were cultured with cytokines GM-CSF, IL-4, and TNFalpha to induce their maturation. The cells cultured with cytokines for 8 days gained the capacity to stimulate allogeneic $T$ cells [67]. Kaneno $R$ et al showed that noncytotoxic concentrations of chemotherapeutic agents do not induce apoptosis of DCs, but directly enhance DC maturation and function. They showed that 5-aza-2-deoxycytidine, methotrexate, and mitomycin C increased the ability of human DCs to stimulate proliferation of allogeneic T lymphocytes [68]. Wilde et al cotransfected autologous dendritic cells with allogeneic MHC molecule and a tumor associated antigen. The allo-restricted peptide specific $T$ cells had superior capacity to recognize tumor cells and higher functional avidity [69]. A subset of human DC, termed DC-10 that express high levels of HLA-G and ILT4, secrete high amounts of IL-10, and induce allospecific Tr1 cells in vitro via an IL-10-dependent ILT4/HLA-G pathway. IL-10, HLA-G, and ILT4 may also be involved in Tr1-cell induction in vivo [70]. CCR9[+] plasmacytoid DCs seem to be potent inducers of regulatory $\mathrm{T}$ cell function and suppressed antigen-specific immune responses both in vitro and in vivo, including inhibiting acute graft-versus-host disease induced by allogeneic CD4[+] donor T cells in irradiated recipients [71].

\subsection{Using fusion therapy}

Cao DY et al fused autologous DCs from patients with hepatocellular carcinoma [HCC] to an allogeneic HCC cell line [HepG2]. These fusion cells co-expressed tumor-associated antigens [TAAs] and DC-derived costimulatory and MHC molecules. Both CD4 [+] and CD8 [+] T cells were activated by the fusion cells. These induced cytotoxic lymphocytes were able to kill autologous HCC. Such cross priming for shared tumor antigens can boost the prospects of adoptive immunotherapy [72].

\subsection{Use of cytokines}

Alloreactive donor-derived $T$ cells from recipients of allogeneic BMT express little IL-7R. Posttransplant IL-7 administration to recipients of an allogeneic BMT enhances lymphoid reconstitution without aggravating GVHD while preserving GVL [73]. Multipeg-G-CSF treatment of donor induces greater levels of progenitor cell, myelogenous, and iNKT cell expansion, while inducing protection from GvHD. iNKT cells, significantly augment CD8+ T cell-mediated cytotoxicity and GVL effects after transplantation. Thus GVL and GVHD can be further separated 
after allogeneic stem cell transplantation by mobilization with a multiple-pegylated G-CSF molecule [74]. IL-11 induces polarization of donor T cells toward type-2 cytokine response by inhibiting the secretion of TNF- $\alpha$ and IL-12 by host macrophages. Thus it can L-11 promotes leukemia-free survival after allogeneic BMT by reducing GVHD while maintaining GVL activity [75].

\subsection{Use of drugs and metabolites}

Rapamycin can increase the ratio of $\mathrm{CD} 4[+] \mathrm{CD} 25[+]$ regulatory $\mathrm{T}$ cells in vitro and prolong the graft survival time obviously after adoptive immunity, and these effects are enhanced by low-dose of IL-2 [76]. Aspirin-treated dendritic cells have the nuclear factor K-B [NFKB] signaling pathway inhibited, modified cytokine production, reduced expression of co-stimulatory molecules [CD40, CD80, and CD86], increased expression of immunoglobulin-like transcript-3 [ILT3] with de novo generation of regulatory $T$ cells. Unlike immature dendritic cells, aspirin-treated DCs have the potential to control unwanted immune-responses such as the indirect pathway of allo-recognition that drives chronic allograft rejection $[77,78]$.

\subsection{Allogeneic therapeutic vaccines}

Complex whole cell-derived vaccines have given clinically superior responses compared to vaccines containing well-defined antigens, such as peptides or gangliosides; however, welldefined vaccines are theoretically more desirable because of their reproducibility [79]. Allogeneic HSCT followed by vaccination with irradiated tumor cells engineered to secrete GM-CSF generates a potent antitumor effect without worsening the toxicities of graft-versus-host disease [GVHD][80]. KGF-treated allo-BMT recipients have an improved ratio of $\mathrm{T}$ effector cells to regulatory $T$ cells. KGF supports thymic epithelial cells and increases thymic output of naive $T$ cells. Hence KGF can function as a potent vaccine adjuvant [81]. Nizar Habal et al developedCancerVax, an allogeneic tumor cell vaccine at the John Wayne Cancer Institute [JWCI]. This vaccine consists of three live human melanoma cell lines chosen for their wide range of tumor-associated antigens [TAA] and major histocompatibility complex antigens. The immune response to CancerVax can cross-react with nonvaccine tumor cells expressing some of the same immunogenic TAA, such as gangliosides [GD2, GM2, GD3, and GM3], glycoproteins [fetal antigen, TA90], and/or proteins [MAGE-1, MAGE-3] [82].

\subsection{Use of siRNA}

STAT3 has been described as an oncogene involved in tumor progression while its expression in immune cells is associated with cancer tolerance. STAT3 inhibition in tumor cells, using siRNA strategies, decreases invasion, angiogenesis, and reduces tumor spreading [83]. Lukemic blasts express HLA-E, which is an inhibitory ligand for CD94+/NKG2A+ NK cells. Tansfusion of in vitro cytokine/Hsp-70 peptide-stimulated NK cells might provide an immunotherapeutic option for treating patients with Hsp70 membrane-positive, HLA E membrane-negative tumors [84] siRNA directed against HLA-E in HLA-E positive leukemic blasts can be a option for this treatment. To induce an effective and long-lasting anti-leukemic $T$ cell response, however, CD4+ T cells are necessary to provide help to CTLs upon activation by APCs[both in autologous and allogeneic settings]. Leukemic blasts express invariant chain intracellularly, as well as HLA-DR [DR] and CLIP at the plasma membrane, which facilitates them to escape immune surveillance by circumventing leukemia-specific CD4+ $T$ cell recognition. Use of li-siRNA directed against CLIP can induce a long lasting anti-leukemic response [85].

\section{Umbilical cord blood transplantation}

Owing to less severe graft vs host disease umbilical cord blood transplantation is seen as an alternative to bone marrow transplantation. Cytokine immunotherapy using IL-15 simultaneously modulates several immune compartments and thus holds promise for facilitating post-transplant recovery and augmenting antitumor effect without aggravating GVHD in the setting of UCB transplantation [86]. Tanaka $\mathrm{J}$ et al expanded cytotoxic CD94-expressing CD8 $\mathrm{T}$ cells from CD4depleted cord blood using an immobilized anti-CD3 monoclonal antibody with concomitant enrichment of CD4[+]CD25[+] regulatory $T$ cells were expanded from a CD4-enriched fraction using anti-CD3/CD28 monoclonal antibody-coated Dynabeads and cytokines. They proposed that 
these expanded cytolytic CD94-expressing CD8 cells might be able to induce a graft-vs-leukemia effect without enhancing graft-vs-host disease, and CD4[+]CD25[+] cells might be able to suppress allogeneic responses, including graft-vs-host disease and graft rejection after cord blood transplantation [87]. It was observed that partial HLA matching of UCB units is preferred since it elicits an enhanced graft vs leukemia effect in acute leukemia patients [88]. UCBT for acute leukemia in CR from KIR-ligand-incompatible donors is associated with decreased RI and improved LFS and OS [89].

\section{Discussion}

The host environment is a major factor influencing the cellular mechanisms of GVL. After transplantation of haploidentical hematopoietic stem cells and infusion of donor T cells, leukemic cells can escape from the donor's antileukemic T cells through the loss of the mismatched HLA haplotype [90]. The failure to identify an HLA null allele as a non-expressed variant in the stem cell transplantation setting may result in an HLA mismatch. This stimulates allogeneic T cells thus ending up in graft-vs-host disease. Some HLA alleles have truncated polypeptides as their translation product, which thus might act as minor histocompatibility antigens. Because the prevalence of HLA null alleles may be around $0.3 \%$ or even higher, an optimal screening strategy for HLA null alleles should be explored [91]. Human leukocyte antigen [HLA] recombination, particularly multiple recombinations can produce novel haplotypes, thereby complicating donorrecipient selection and possibly inducing severe graft-vs-host disease [GVHD] after nonfully matched allogeneic hematopoietic stem cell transplantation [92]. Worthley DL etal identified 18 patients with solid organ neoplasia that developed in female recipients of male allogeneic stem cell transplants [93]. The above issues need to be considered, in view of optimization of bone marrow transplantation. Superior immune plasticity of cord blood [CB] grafts that allows for less stringent HLA matching is especially valuable in the face of a persistently growing need for unrelated donor transplants. CB may become a frontline hematopoietic stem cell [HSC] source for transplantation, especially in children with leukemia. However, the technique needs to be a lot optimized for transplantation into adults. CB treated patients seem to have lesser neutrophil and platelet counts than the BM transplant patients. UCB transplant patients are more likely to die of infection [94]. Immunomodulation of the allogeneic bone marrow, seems to be the key for maximal separation of GvHD and GvL. Stem cell mobilization of donor bone marrow with G-CSF polarizes conventional alphabeta $\mathrm{T}$ cells toward a $\mathrm{TH} 2$ pattern of cytokine production, Studies done to date suggest that if GVHD is CD4 dependent and GVL effects are mediated by CD8+ CTL and NK cell, then G-CSF mediated separation of GVH and GVL will be most marked.[95]The transfer of donor Th2-type cells may be an important strategy for regulating GVHD Delayed donor Th2 cell infusion permits a graft-versus-tumor [GVT] effect to occur with subsequent amelioration of established graft-versus-host disease [GVHD][96]. Significant enthusiasm has emerged for manipulating Treg either ex vivo or in vivo for clinical benefit. Allospecific $T$ cells can have effector or regulatory functions, and the relative proportions of the two populations activated following alloantigen presentation are two of the factors that determine the clinical outcome [97]. Tregs present in 1:1 ratio with effector $T$ cells do not block $T$ cell activation but seem to decrease the early proliferation responsible for aGVHD [98]. A certain critical level of host B cells seems to reduce the graft vs host disease through IL-10 mediated mediated inhibition of alloreactive $\mathrm{T}$ cell expansion [99]. The above observations make us think, what could be an ideal allogeneic donor bone marrow? Probably a marrow with helper T cells skewed towards Th2 profile, greater levels of NK, NKT and importantly regulatory $T$ cells and regulatory dendritic cells. This may require pretreatment of donor bone marrow with requisite cytokines like multipegylated G-CSF, IL-4, IL11 as well as requisite drugs and metabolites. This can be followed by siRNA based strategies to regulate cytokine profile in the recipient. At the same time reduced intensity conditioning of recipient can help in reducing GvHD. To keep a sustained GvL, post transplantation, delayed Th2 infusion and allogeneic therapeutic vaccines have a great potential. Similarly in vivo transfer of allogeneic MHC genes [100,69] into tumors can further help in maintaining a threshold GvL. Optimization of this former technique as well as its extension to solid tumors need to be explored. There is a critical bottleneck in identifying high-affinity TCR specificities needed to treat different malignancies which is the reason, for shift of focus towards APC cells [69]. Also donor T cells clones specific for pathogens like Aspergillus, and Vyto megalovirus can significantly reduce 
the incidence of infections [101]. Minor $\mathrm{H}$ antigens have a broader clinical outcome, both in haematopoietic stem cell transplantation and in solid organ transplantation [102].

\title{
9. Conclusion and Future Prospects
}

An optimal bone marrow transplantation program with not just minimal GvHD but a sustained anti-leukemic effect, post transplantation is the need of the hour, for leukemia patients, especially for adults and old. There is a significant scope for insigtfull research into utilization of tumor specific antigens, siRNA based and in vivo efficient transfection strategies punctuated with increased understanding of $\mathrm{MHC}$ restriction between donor [especially immunomodulatory cells] and recipient cells. Also we cannot deny underlining the potential of allogeneic therapeutic vaccines. The wait for finding a suitable donor bone marrow is long. Further developments in peripheral and cord blood stem cell transplantation can help in proving as an alternative for leukemia patients, at least in children. Also the extension of techniques based on the principle of alloreactivity with enhanced understanding of miHA in context of MHC restriction; need to be explored for solid tumors.

\author{
Abbreviations \\ GVH- graft versus host \\ GVHD- GVH disease \\ GVL- graft versus leukemia \\ AML- acute myeloid leukemia \\ TCR- T cell receptor \\ MLR- mixed leukocyte reaction \\ IT- immunotoxin
}

\section{Reference}

[1] Lang K, Entschladen F, Weidt C, Zaenker KS.[ 2006] Tumor immune escape mechanisms: impact of the neuroendocrine system. Cancer Immunol Immunother.55[7]:749-60

[2] Botti C, Seregni E, Ferrari L, Martinetti A, Bombardieri E.[1998] Immunosuppressive factors: role in cancer development and progression. Int J Biol Markers. 13[2]:51-69

[3] M.J. Garlepp, C.C. Leong[1995,] Biological and immunological aspects of malignant mesothelioma Eur Respir J, 8, 643-650

[4] Chakraverty R, Sykes M.[ 2007] The role of antigen-presenting cells in triggering graftversus-host disease and graft-versus-leukemia. Blood110[1]:9-17

[5] Detours V, Perelson AS.[2000] The paradox of alloreactivity and self MHC restriction: quantitative analysis and statistics. Proc Natl Acad Sci U S A. 97[15]:8479-83.

[6] Nesic D, Maric M, Santori FR, Vukmanovic S[2002]. Factors influencing the patterns of T lymphocyte allorecognition. Transplantation.73 [5]:797-803.

[7] Hornell TM, Myers N, Hansen TH, Connolly JM.[2003] Homology between an alloantigen and a self $\mathrm{MHC}$ allele calibrates the avidity of the alloreactive $\mathrm{T}$ cell repertoire independent of TCR affinity. J Immunol. 170[9]:4506-14.

[8] Whitelegg A, Barber LD.[2004] The structural basis of T-cell allorecognition. Tissue Antigens.63[2]:101-8

[9] Slavin S.[2002] Maternal-fetal relationship, natural chimerism and bilateral transplantation tolerance as the basis for non-myeloablative stem cell transplantation. Int $\mathrm{J}$ Hematol. 76 Suppl 1:172-5.

[10] Erikci AA, Karagoz B, Ozyurt M, Ozturk A, Kilic S, Bilgi O.[2009] HLA-G expression in B chronic lymphocytic leukemia: a new prognostic marker? Hematology,14[2]:101-5

[11] Feng X, Hui KM, Younes HM, Brickner AG.[2008] Targeting minor histocompatibility antigens in graft versus tumor or graft versus leukemia responses. Trends Immunol. [12]:624-32

[12] Parkman R.[1989] Graft-versus-host disease: an alternative hypothesis. Immunol Today. 10[11]:362-4.

[13] Ferrara JL, Cooke KR, Teshima T. [2003] The pathophysiology of acute graft-versus-host disease. nt J Hematol.78[3]:181-7. 
[14] Tawara I, Maeda Y, Sun Y, Lowler KP, Liu C, Toubai T, McKenzie AN, Reddy P. [2008] Combined Th2 cytokine deficiency in donor T cells aggravates experimental acute graftvs-host disease. Exp Hematol. 36[8]:988-96.

[15] Blazar BR, Murphy WJ. [2005] Bone marrow transplantation and approaches to avoid graftversus-host disease [GVHD]. Philos Trans R Soc Lond B Biol Sci. 360[1461]:1747-67

[16] Reddy P. [2003] Pathophysiology of acute graft-versus-host disease. Hematol Oncol. 21[4]:149-61.

[17] Nogueira-Martins MF, Mariano M.[2009] B-1 cell participation in T-cell-mediated alloimmune response. Immunobiology. [Epub ahead of print]

[18] Ikehara S.[2000] Pluripotent hemopoietic stem cells in mice and humans. Proc Soc Exp Biol Med. 223[2]:149-55.

[19] Ikehara S.[2001] Successful allogeneic bone marrow transplantation. Crucial roles of stromal cells in prevention of graft rejection. Acta Haematol. 105[3]:172-8.

[20] Nasef A, Zhang YZ, Mazurier C, Bouchet S, Bensidhoum M, Francois S, Gorin NC, Lopez M, Thierry D, Fouillard L, Chapel A.[2009] Selected Stro-1-enriched bone marrow stromal cells display a major suppressive effect on lymphocyte proliferation. Int $\mathrm{J}$ Lab Hematol31[1]:9-19

[21] Murphy B, Yu J, Jiao Q, Lin M, Chitnis T, Sayegh MH.[2003] A novel mechanism for the immunomodulatory functions of class II MHC-derived peptides. J Am Soc Nephrol. 14[4]:1053-65.

[22] Petersen SL.[2007] Alloreactivity as therapeutic principle in the treatment of hematologic malignancies Studies of clinical and immunologic aspects of allogeneic hematopoietic cell transplantation with nonmyeloablative conditioning. Dan Med Bull. 54[2]:112-39.

[23] Capitini CM, Herby S, Milliron M, Anver MR, Mackall CL, Fry TJ.[2009] Bone marrow deficient in IFN-\{gamma\} signaling selectively reverses GVHD-associated immunosuppression and enhances a tumor-specific GVT effect. Blood. 113[20]:5002-9. Epub 2009 Mar 3.

[24] Overes IM, Fredrix H, Kester MG, Falkenburg JH, van der Voort R, de Witte TM, Dolstra H.[2009] Efficient activation of LRH-1-specific CD8+ T-cell responses from transplanted leukemia patients by stimulation with P2X5 mRNA-electroporated dendritic cells. $J$ Immunother. ;32[6]:539-51.

[25] Rezvani AR, Storb RF. [2008] Separation of graft-vs.-tumor effects from graft-vs.-host disease in allogeneic hematopoietic cell transplantation. J Autoimmun; 30[3]:172-9. .

[26] Lu Y, Waller EK.[2009] Dichotomous role of interferon-gamma in allogeneic bone marrow transplant. Biol Blood Marrow Transplant.15[11]:1347-53.

[27] Kawase T, Matsuo K, Kashiwase K, Inoko H, Saji H, Ogawa S, Kato S, Sasazuki T, Kodera Y, Morishima Y; Japan Marrow Donor Program.[2009] HLA mismatch combinations associated with decreased risk of relapse: implications for the molecular mechanism. Blood.113[12]:2851-8. Epub 2008 Nov 7.

[28] Chakraverty R, Eom HS, Sachs J, Buchli J, Cotter P, Hsu R, Zhao G, Sykes M. [2006] Host MHC class II+ antigen-presenting cells and CD4 cells are required for CD8-mediated graft-versus-leukemia responses following delayed donor leukocyte infusions. Blood 108[6]:2106-13. Epub 2006 Jun 6.

[29] Nishida T, Hudecek M, Kostic A, Bleakley M, Warren EH, Maloney D, Storb R, Riddell SR.[2009] Development of tumor-reactive $T$ cells after nonmyeloablative allogeneic hematopoietic stem cell transplant for chronic lymphocytic leukemia. Clin Cancer Res.15[14]:4759-68. Epub 2009 Jun 30.

[30] Quintarelli C, Dotti G, De Angelis B, Hoyos V, Mims M, Luciano L, Heslop HE, Rooney CM, Pane F, Savoldo B.[2008] Cytotoxic $T$ lymphocytes directed to the preferentially expressed antigen of melanoma [PRAME] target chronic myeloid leukemia. Blood.112[5]:1876-85. Epub 2008 Jun 30

[31] Akatsuka Y, Morishima Y, Kuzushima K, Kodera Y, Takahashi T.[2007] Minor histocompatibility antigens as targets for immunotherapy using allogeneic immune reactions. Cancer Sci. 98[8]:1139-46. Epub 2007 May 22

[32] Spierings E, Hendriks M, Absi L, Canossi A, Chhaya S, Crowley J, Dolstra H, Eliaou JF, Ellis T, Enczmann J, Fasano ME, Gervais T, Gorodezky C, Kircher B, Laurin D, Leffell MS, 
Loiseau P, Malkki M, Markiewicz M, Martinetti M, Maruya E, Mehra N, Oguz F, Oudshoorn M, Pereira N, Rani R, Sergeant R, Thomson J, Tran TH, Turpeinen H, Yang $\mathrm{KL}$, Zunec R, Carrington M, de Knijff P, Goulmy E. [2007]Phenotype frequencies of autosomal minor histocompatibility antigens display significant differences among populations. PLoS Genet.;3[6]:e103.

[33] Imanguli MM, Alevizos I, Brown R, Pavletic SZ, Atkinson JC.[2008] Oral graft-versus-host disease. Oral Dis. ;14[5]:396-412

[34] Goulmy E.[2006] Minor histocompatibility antigens: from transplantation problems to therapy of cancer. Hum Immunol. ;67[6]:433-8. Epub 2006 Apr 6. Review

[35] Ruggeri L, Capanni M, Mancusi A, Urbani E, Perruccio K, Burchielli E, Tosti A, Topini F, Aversa F, Martelli MF, Velardi A.[2004] Alloreactive natural killer cells in mismatched hematopoietic stem cell transplantation. Blood Cells Mol Dis. 33[3]:216-21.

[36] Bensa JC[2003]. The major histocompatibility complex as self-referential. Transfus Clin Biol. [3]:209-13.

[37] Kolb HJ, Schmid C, Barrett AJ, Schendel DJ[2004]. Graft-versus-leukemia reactions in allogeneic chimeras. Blood. ;103[3]:767-76.

[38] Zhao XY, Huang XJ.[2007] [Influence factors of reconstitution of killer cell immunoglobulinlike receptor on NK cells following non-T-cell-depleted haploidentical hematopoietic stem cell transplantation] Zhonghua Xue Ye Xue Za Zhi. 8[2]:103-6. Chinese.

[39] Parham P, McQueen KL.[2003] Alloreactive killer cells: hindrance and help for haematopoietic transplants. Nat Rev Immunol. 3[2]:108-22

[40] Shaulov A, Yue S, Wang R, Joyce RM, Balk SP, Kim HT, Avigan DE, Uhl L, Sackstein R, Exley MA.[2008] Peripheral blood progenitor cell product contains Th1-biased noninvariant CD1d-reactive natural killer T cells: implications for posttransplant survival. Exp Hematol. 36[4]:464-72. Epub 2008

[41] Fujii S.[2005] Application of natural killer T-cells to posttransplantation immunotherapy. Int J Hematol. 81[1]:1-5.

[42] Sanchez-Fueyo A, Sandner S, Habicht A, Mariat C, Kenny J, Degauque N, Zheng XX, Strom TB, Turka LA, Sayegh MH.[2006] Specificity of CD4+CD25+ regulatory T cell function in alloimmunity. J Immunol.;176[1]:329-34.

[43] Akasaki Y, Liu G, Chung NH, Ehtesham M, Black KL, Yu JS.[2004] Induction of a CD4+ T regulatory type 1 response by cyclooxygenase-2-overexpressing glioma. $J$ Immunol;173[7]:4352-9.

[44] Hall BM, Tran G, Hodgkinson SJ[2009]. Alloantigen specific T regulatory cells in transplant tolerance. Int Immunopharmacol.;9[5]:570-4. Epub 2009 Jan 29

[45] Verma ND, Plain KM, Nomura M, Tran GT, Robinson C, Boyd R, Hodgkinson SJ, Hall BM.[2009] CD4+CD25+ T cells alloactivated ex vivo by IL-2 or IL-4 become potent alloantigen-specific inhibitors of rejection with different phenotypes, suggesting separate pathways of activation by Th1 and Th2 responses. Blood.;113[2]:479-87

[46] Li AH, Qiu GQ, Gu WY, Ling Y, Weng KZ, Tan Q, Cao XS.[2007] Expression of CD4+ CD25+ regulatory $T$ cells in the patients with acute lymphocytic leukemia] Xi Bao Yu Fen Zi Mian Yi Xue Za Zhi. 23[5]:439-42.

[47] Cao J, Chen C, Zeng L, Li L, Li Z, Xu K.[2009] Engineered regulatory T cells prevent graftversus-host disease while sparing the graft-versus-leukemia effect after bone marrow transplantation. Leuk Res. [Epub ahead of print]

[48] Guillot-Delost M, Cherai M, Hamel Y, Rosenzwajg M, Baillou C, Simonin G, Leclercq V, Mariotti-Ferrandiz ME, Six A, Bon-Durand V, Maury S, Salomon BL, Cohen JL, Klatzmann D, Lemoine FM.[2008] Clinical-grade preparation of human natural regulatory T-cells encoding the thymidine kinase suicide gene as a safety gene. J Gene Med. 10[8]:834-46

[49] Maeda A. Extracorporeal photochemotherapy.[2009] J Dermatol Sci.;54[3]:150-6.

[50] Akatsuka Y, Morishima Y, Kuzushima K, Kodera Y, Takahashi T[2007] Minor histocompatibility antigens as targets for immunotherapy using allogeneic immune reactions. Cancer Sci. ;98[8]:1139-46

[51] Nicholls S, Piper KP, Mohammed F, Dafforn TR, Tenzer S, Salim M, Mahendra P, Craddock C, van Endert P, Schild H, Cobbold M, Engelhard VH, Moss PA, Willcox BE.[2009] 
Secondary anchor polymorphism in the HA-1 minor histocompatibility antigen critically affects MHC stability and TCR recognition. Proc Natl Acad Sci U S A. 106[10]:3889-94.

[52] Hambach L, Ling KW, Pool J, Aghai Z, Blokland E, Tanke HJ, Bruijn JA, Halfwerk H, van Boven H, Wieles B, Goulmy E.[2009] Hypomethylating drugs convert HA-1-negative solid tumors into targets for stem cell-based immunotherapy. Blood. ;113[12]:2715-22.

[53] Di Terlizzi S, Zino E, Mazzi B, Magnani C, Tresoldi C, Perna SK, Bregni M, Rossini S, Ciceri F, Bordignon C, Bonini C, Fleischhauer K.[2006] Therapeutic and diagnostic applications of minor histocompatibility antigen HA-1 and HA-2 disparities in allogeneic hematopoietic stem cell transplantation: a survey of different populations Biol Blood Marrow Transplant. 12[1]:95-101

[54] Meunier MC, Baron C, Perreault C[2009] Two host factors regulate persistence of H7specific $T$ cells injected in tumor-bearing mice. PLoS One. ;4[1]:e4116

[55] Overes IM, de Rijke B, van Horssen-Zoetbrood A, Fredrix H, de Graaf AO, Jansen JH, van Krieken JH, Raymakers RA, van der Voort R, de Witte TM, Dolstra H.[2008] Expression of $\mathrm{P} 2 \mathrm{X} 5$ in lymphoid malignancies results in LRH-1-specific cytotoxic T-cell-mediated lysis. Br J Haematol. 141[6]:799-807

[56] Spierings E, Goulmy E.[2005] Expanding the immunotherapeutic potential of minor histocompatibility antigens. J Clin Invest.115[12]:3397-400.

[57] Stumpf AN, van der Meijden ED, van Bergen CA, Willemze R, Falkenburg JH, Griffioen M. [2009]Identification of 4 new HLA-DR-restricted minor histocompatibility antigens as hematopoietic targets in antitumor immunity. Blood.;114[17]:3684-92.

[58] Leo Luznik, MD, and Ephraim J. Fuchs, MD[2002] Donor Lymphocyte Infusions to Treat Hematologic Malignancies in Relapse After Allogeneic Blood or Marrow Transplantation. Cancer Control, Vol. 9, No.2

[59] Tomblyn M, Lazarus HM.[2008] Donor lymphocyte infusions: the long and winding road: how should it be traveled? Bone Marrow Transplant.;42[9]:569-79

[60] Frey NV, Porter DL. [2008] Graft-versus-host disease after donor leukocyte infusions: presentation and management. Best Pract Res Clin Haematol. ;21[2]:205-22

[61] Fowler DH, Gress RE.[2000] Th2 and Tc2 cells in the regulation of GVHD, GVL, and graft rejection: considerations for the allogeneic transplantation therapy of leukemia and lymphoma. Leuk Lymphoma. ;38[3-4]:221-34

[62] Xia G, Truitt RL, Johnson BD.[2006] Graft-versus-leukemia and graft-versus-host reactions after donor lymphocyte infusion are initiated by host-type antigen-presenting cells and regulated by regulatory $\mathrm{T}$ cells in early and long-term chimeras. Biol Blood Marrow Transplant. ;12[4]:397-407.

[63] Ge X, Brown J, Sykes M, Boussiotis VA.[2008] CD134-allodepletion allows selective elimination of alloreactive human $\mathrm{T}$ cells without loss of virus-specific and leukemiaspecific effectors. Biol Blood Marrow Transplant. 14[5]:518-30.

[64] Heslop HE, Stevenson FK, Molldrem JJ.[2003] Immunotherapy of hematologic malignancy. Hematology Am Soc Hematol Educ Program. :331-49

[65] Tey SK, Dotti G, Rooney CM, Heslop HE, Brenner MK[2007]. Inducible caspase 9 suicide gene to improve the safety of allodepleted $\mathrm{T}$ cells after haploidentical stem cell transplantation. Biol Blood Marrow Transplant. 13[8]:913-24

[66] Perruccio K, Topini F, Tosti A, Carotti A, Aloisi T, Aversa F, Martelli MF, Velardi A .[2008]Photodynamic purging of alloreactive $T$ cells for adoptive immunotherapy after haploidentical stem cell transplantation. Blood Cells Mol Dis. ;40[1]:76-83

[67] Li YL, Wu YG, Wang YQ, Li Z, Wang RC, Wang L, Zhang YY.[2008] Bone marrow-derived dendritic cells pulsed with tumor lysates induce anti-tumor immunity against gastric cancer ex vivo. World J Gastroenterol.;14[46]:7127-32

[68] Kaneno R, Shurin GV, Tourkova IL, Shurin MR[2009]. Chemomodulation of human dendritic cell function by antineoplastic agents in low noncytotoxic concentrations. J Transl Med.; $7: 58$.

[69] Wilde S, Sommermeyer D, Frankenberger B, Schiemann M, Milosevic S, Spranger S, Pohla H, Uckert W, Busch DH, Schendel DJ.[2009] Dendritic cells pulsed with RNA encoding allogeneic $\mathrm{MHC}$ and antigen induce $\mathrm{T}$ cells with superior antitumor activity and higher TCR functional avidity. Blood.;114[10]:2131-9. 
[70] Gregori S, Magnani CF, Roncarolo MG. Role of human leukocyte antigen-G in the induction of adaptive type 1 regulatory T cells Hum Immunol. 2009 Dec;70[12]:966-9.

[71] Hadeiba H, Sato T, Habtezion A, Oderup C, Pan J, Butcher EC[2008]. CCR9 expression defines tolerogenic plasmacytoid dendritic cells able to suppress acute graft-versus-host disease. Nat Immunol. 9[11]:1253-60

[72] Cao DY, Yang JY, Yue SQ, Tao KS, Song ZS, Wang DS, Yang YL, Dou KF. [2009] Comparative analysis of DC fused with allogeneic hepatocellular carcinoma cell line HepG2 and autologous tumor cells as potential cancer vaccines against hepatocellular carcinoma. Cell Immunol.;259[1]:13-20

[73] Alpdogan O, Schmaltz C, Muriglan SJ, Kappel BJ, Perales MA, Rotolo JA, Halm JA, Rich $B E$, van den Brink MR. Administration of interleukin-7 after allogeneic bone marrow transplantation improves immune reconstitution without aggravating graft-versus-host disease. Blood. 2001 Oct 1;98[7]:2256-65.

[74] Banovic T, MacDonald KP, Markey KA, Morris ES, Kuns RD, Varelias A, Hill GR.[2009]Donor treatment with a multipegylated G-CSF maximizes graft-versusleukemia effects. Biol Blood Marrow Transplant.15[1]:126-30.

[75] Teshima T, Hill GR, Pan L, Brinson YS, van den Brink MR, Cooke KR, Ferrara JL. [1999]L11 separates graft-versus-leukemia effects from graft-versus-host disease after bone marrow transplantation J Clin Invest. ;104[3]:317-25.

[76] Zheng YX, Hou GH, Song J, Zhang C, Liang T.[2007] Effect of Rapamycin on CD4[+] CD25[+] regulatory $T$ cells in allo-transplantation tolerance model. Xi Bao Yu Fen Zi Mian Yi Xue Za Zhi. ;23[4]:327-30.

[77] Buckland M, Jago C, Fazekesova H, George A, Lechler R, Lombardi G.[2006] Aspirin modified dendritic cells are potent inducers of allo-specific regulatory T-cells. Int Immunopharmacol. ;6[13-14]:1895-901.

[78] Buckland M, Lombardi G.[2009] Aspirin and the induction of tolerance by dendritic cells. Handb Exp Pharmacol. ;[188]:197-213.

[79] Mitchell MS.[2002] Cancer vaccines, a critical review--Part I. Curr Opin Investig Drugs.;3[1]:140-9

[80] Ho VT, Vanneman M, Kim H, Sasada T, Kang YJ, Pasek M, Cutler C, Koreth J, Alyea E, Sarantopoulos S, Antin JH, Ritz J, Canning C, Kutok J, Mihm MC, Dranoff G, Soiffer R.[2009] Biologic activity of irradiated, autologous, GM-CSF-secreting leukemia cell vaccines early after allogeneic stem cell transplantation. Proc Natl Acad Sci U S A.;106[37]:15825-30

[81] Jenq RR, King CG, Volk C, Suh D, Smith OM, Rao UK, Yim NL, Holland AM, Lu SX, Zakrzewski JL, Goldberg GL, Diab A, Alpdogan O, Penack O, Na IK, Kappel LW, Wolchok JD, Houghton AN, Perales MA, van den Brink MR. [2009]Keratinocyte growth factor enhances DNA plasmid tumor vaccine responses after murine allogeneic bone marrow transplantation Blood.;113[7]:1574-80.

[82] Nizar Habal, MD, Rishab K. Gupta, PhD, Anton J. Bilchik, MD, PhD, Reynold Yee, BS, Zacharias Leopoldo, DDM, Wei Ye, MS, Robert M. Elashoff, PhD and Donald L. Morton, MD.[2001] CancerVax, An Allogeneic Tumor Cell Vaccine, Induces Specific Humoral and Cellular Immune Responses in Advanced Colon Cancer. Annals of Surgical Oncology 8:389-401

[83] Pallandre JR, Brillard E, Créhange G, Radlovic A, Remy-Martin JP, Saas P, Rohrlich PS, Pivot X, Ling X, Tiberghien P, Borg C.[2007] Role of STAT3 in CD4+CD25+FOXP3+ regulatory lymphocyte generation: implications in graft-versus-host disease and antitumor immunity. J Immunol.;179[11]:7593-604

[84] Stangl S, Gross C, Pockley AG, Asea AA, Multhoff G.[2008] Influence of Hsp70 and HLA-E on the killing of leukemic blasts by cytokine/Hsp70 peptide-activated human natural killer [NK] cells. Cell Stress Chaperones. 13[2]:221-30

[85] van Luijn MM, Chamuleau ME, Thompson JA, Ostrand-Rosenberg S, Westers TM, Souwer Y, Ossenkoppele GJ, van Ham SM, van de Loosdrecht AA.[2009] CLIP down-modulation enhances the immunogenicity of myeloid leukemic blasts resulting in increased CD4+ T cell responses. Haematologica. 2009 Nov 10. 
[86] Lin SJ, Yan DC, Lee YC, Kuo ML.[2008] Role of interleukin-15 in umbilical cord blood transplantation. Int Rev Immunol.;27[6]:518-31.

[87] Tanaka J, Sugita J, Kato N, Toubai T, Ibata M, Shono Y, Ota S, Kondo T, Kobayashi T, Kobayashi M, Asaka M, Imamura M.[2007] Expansion of natural killer cell receptor [CD94/NKG2A]-expressing cytolytic CD8 T cells and CD4+CD25+ regulatory T cells from the same cord blood unit. Exp Hematol. ;35[10]:1562-6.

[88] Verneris MR, Brunstein CG, Barker J, MacMillan ML, DeFor T, McKenna DH, Burke MJ, Blazar BR, Miller JS, McGlave PB, Weisdorf DJ, Wagner JE[2009]. Relapse risk after umbilical cord blood transplantation: enhanced graft-versus-leukemia effect in recipients of 2 units. Blood.;114[19]:4293-9.

[89] Willemze R, Rodrigues CA, Labopin M, Sanz G, Michel G, Socié G, Rio B, Sirvent A, Renaud M, Madero L, Mohty M, Ferra C, Garnier F, Loiseau P, Garcia J, Lecchi L, Kögler G, Beguin Y, Navarrete C, Devos T, lonescu I, Boudjedir K, Herr AL, Gluckman E, Rocha V; Eurocord-Netcord and Acute Leukaemia Working Party of the EBMT[2009]. KIR-ligand incompatibility in the graft-versus-host direction improves outcomes after umbilical cord blood transplantation for acute leukemia. Leukemia. 23[3]:492-500

[90] Vago L, Perna SK, Zanussi M, Mazzi B, Barlassina C, Stanghellini MT, Perrelli NF, Cosentino C, Torri F, Angius A, Forno B, Casucci M, Bernardi M, Peccatori J, Corti C, Bondanza A, Ferrari M, Rossini S, Roncarolo MG, Bordignon C, Bonini C, Ciceri F, Fleischhauer K.[2009] Loss of mismatched HLA in leukemia after stem-cell transplantation. N Engl J Med.;361[5]:478-88

[91] Elsner HA, Blasczyk R.[2004] Immunogenetics of HLA null alleles: implications for blood stem cell transplantation. Tissue Antigens.;64[6]:687-95.

[92] Sun Y, Kong F, Ren S, Yuan F, Liang F, Liu N, Jin L, Xi Y[2007]. Severe acute graft-vs-host disease in a patient with acute monocytic leukemia having a recombination event between HLA-A/B loci from a multiple recombinant family Tissue Antigens.;70[6]:499505.

[93] Worthley DL, Ruszkiewicz A, Davies R, Moore S, Nivison-Smith I, Bik To L, Browett P, Western R, Durrant S, So J, Young GP, Mullighan CG, Bardy PG, Michael MZ.[2009]. Human gastrointestinal neoplasia-associated myofibroblasts can develop from bone marrow-derived cells following allogeneic stem cell transplantation. Stem Cells.;27[6]:1463-8.

[94] Brown JA, Boussiotis VA[2008] Umbilical cord blood transplantation: basic biology and clinical challenges to immune reconstitution. Clin Immunol. 127[3]:286-97

[95] Morris ES, MacDonald KP, Hill GR[2006] Stem cell mobilization with G-CSF analogs: a rational approach to separate GVHD and GVL? Blood.;107[9]:3430-5

[96] Foley JE, Mariotti J, Ryan K, Eckhaus M, Fowler DH.[2008] Th2 cell therapy of established acute graft-versus-host disease requires IL-4 and IL-10 and is abrogated by IL-2 or hosttype antigen-presenting cells. Biol Blood Marrow Transplant.;14[9]:959-72.

[97] Afzali B, Lombardi G, Lechler RI.[2008] Pathways of major histocompatibility complex allorecognition. Curr Opin Organ Transplant.;13[4]:438-44

[98] Joseph Pidala and Claudio Anasetti.[2009] Can antigen-specific regulatory $T$ cells protect against graft vs. host disease and spare anti-malignancy alloresponse? Haematologica.. [Epub ahead of print]

[99] Rowe V, Banovic T, MacDonald KP, Kuns R, Don AL, Morris ES, Burman AC, Bofinger HM, Clouston AD, Hill GR.[2006] Host B cells produce IL-10 following TBI and attenuate acute GVHD after allogeneic bone marrow transplantation. Blood.;108[7]:2485-92

[100] Shimizu H, Nukui Y, Mitsuhashi N, Kimura F, Yoshidome H, Ohtsuka M, Kato A, Miyazaki M.[2009] Induction of antitumor response by in vivo allogeneic major histocompatibility complex gene transfer using electroporation. J Surg Res;154[1]:60-7.

[101] Perruccio K, Tosti A, Burchielli E, Topini F, Ruggeri L, Carotti A, Capanni M, Urbani E, Mancusi A, Aversa F, Martelli MF, Romani L, Velardi A. [2005]Transferring functional immune responses to pathogens after haploidentical hematopoietic transplantation. Blood.;106[13]:4397-406.

[102] Spierings E.[2008] Minor histocompatibility antigens: targets for tumour therapy and transplant tolerance. Int J Immunogenet [4-5]:363-6. 